\title{
USES OF ELECTRONIC MEDIA IN COLLEGE CLASSES: A SURVEY OF MANDI BAHA-UD-DIN AND BHALWAL COLLEGES
}

\author{
Erum Gul \\ Ph.D. Scholar, \\ Department of History, Quaid-e-Azam University, \\ Islamabad, Pakistan \\ Email: erumsajid1@gmail.com
}

\begin{abstract}
The paper explores the use of electronic media in college level classes in smaller cities of Punjab province. It is argued if electronic media is used in classes by the college teachers in the classes, it can enhance effectiveness and also learning to the part of the students. It may attract students, creating in them more interest in class activities and sharing of knowledge. The use of electronic devices and different applications; YouTube, Facebook, WhatsApp and electronic mails, and search engines such as Google Chrome, internet explorer, Mozilla Firefox etc., inculcates enthusiasm among the students and the teacher performance can become livelier fulfilling the objectives of learning in the class. The study has been undertaken by surveying a number of college teachers from various areas of the province of Punjab. Its results manifest that there is an increase of use of electronic media by the teachers in preparation as well as delivery of lectures. They also motivate the students to use these resources for learning skills. The study concludes if regular application of such technologies is made possible as a vibrant variable it would play a vital contribution to institutional competitiveness, improve the learning and teaching experience and meet students' growing expectations of improved use of ICT (Sweeney, 2009).
\end{abstract}

\section{KEYWORDS}

Electronic media, Google, Punjab colleges, WhatsApp, YouTube, electronic mail.

\section{INTRODUCTION}

The more that information and communication technologies become central to modern society, the more it is imperative to identify, and to manage the development of the skills and abilities required to use them. Within both academic and policy discourses, the concept of media literacy is being extended from its traditional focus on print and audiovisual media to encompass the internet and other new and latest media applications. Hence, there is widespread speculation regarding supposedly new forms of literacy - variously termed computer literacy, internet literacy, cyber-literacy, and 
so forth. (Livingstone, 2003) Today, students in the class are more aware and enthusiastic as a large number of them have cell phones or computer at hand for using any social media applications. As Bazalgette states that Children growing up in the 21 st century need to understand the full range of media available to them, both as sources of information and entertainment, and as a means of communicating and sharing ideas. Consequently, a teacher has to be prepared for this encounter in the class and the outer panorama. That is why this study aims at knowing the extent of the use of electronic media by the teachers. Further, they may also improve teacherstudent active communication widening the sharing between them as well as among the teachers themselves. Teachers now, are necessarily in need of knowing and applying of extensive use of electronic media. Though, in an increasingly digital world, media is an essential part of good teaching, as a tool to teach the more traditional aspects of the curriculum. It is now an essential part of literacy, however, in Pakistan very often teacher community is not linked with such modern techniques, is also manifested in this study.

\section{LITERATURE REVIEW}

With the increasing importance of the electronic media, a valuable material is now available depicting its importance, uses and prospects in future. However, these are mostly students-centered, so the information was collected mostly by the research undertaken via survey (Questionnaire as a tool) and its results has been focused to evaluate the hypothesis and its variables adopted. However, a brief literature survey of the material used in this study is incorporated here. Carry states in his book, embedded in the primary (as well as higher) curriculum, that media education enables children to become more fully literate for the digital age. Grounded in best classroom practice, this book aims to help teacher think about the role of media in children's lives, and to teach about media effectively in the classroom. The Chicago Handbook for teachers gives a useful introduction of the electronic resources that complement the conventional way of teaching. Valdemar Setzer defines different types of media namely TV, Radio and Internet. Paula Chimenti conducted a survey to evaluate the use and effects of electronic media in Brazil. Place is different here but the theory is same so it helped in constructing this study too. Ms. Puja discussed Positive Effects of Electronic Media on Society and Culture in her essay. Similarly, S. Arulchelvan stated the role and effectiveness of this very aspect of media. During Corona Pandemic 20202021 , vast research has been undertaking by research agencies at national as well as global level. McKinsey Insights are frequently uploading their experts insights regarding educational issues which stake holders in education have been entangling world over. These reports do probe into the developing countries and their limitations in coping with the socio-economic issues. Similarly, Macro Pakistani is a national level research-oriented agency which is struggling to find out the problems and their solutions in economic context. The author has stated her observations as a participant 
observer as she as a college teacher has been a part of the process of teaching on line while using online applications of WhatsApp, Zoom, google classroom etc. She and her colleagues in a smaller city have been facing a unique set of problems to approach students for making a class and to make them responsive. The problems turns to a serious note when gender difference is involved. These observations and experiences are enumerated under the head of Pandemic discussion.

\section{RESEARCH OBJECTIVE}

1. To find out the acceptance and use of electronic media by the teachers in the process of learning in the class.

2. And to propose the factors that impact the pedagogical methodology of teaching by using electronic media and internet.

3. Significance of the use of this methodology during Pandemic like Corona Pandemic.

4. Response of the teachers in using this very media during the pandemic.

\section{RESEARCH QUESTION}

1. In a developing country like Pakistan, how the effectiveness of this methodology; electronic media, mobile technology and internet applications may be exercised?

2. What the college teachers opine to make the pedagogical methodology more effective by using these methods and revolutionizing the concept of learning?

\section{RESEARCH HYPOTHESIS}

1. Use of electronic media can enhance the potential of learning process in the class with ease and speed.

2. It may widen the scope of studies and introduce the new horizons of education to the teachers as well as the students.

3. It may help teaches to reinvigorate in their students the interest and zeal of learning.

\section{RESEARCH METHODOLOGY}

A survey was conducted for this study and a number of college teachers were given questionnaire, which comprised 10 statements with scale defined. Specimen is annexed in annexure I. It was an effort to know the perceptions about different aspects of pedagogical teaching and learning by asking questions and seeking the views of the teachers of the colleges about modern technology of Mobile Phones, laptops, and internet along with the application uses for sharing knowledge. A population of about 50 lecturers and professors were interviewed by a questionnaire via WhatsApp and Yahoo Messenger, however only 26 replied of these. Data was collected and analyzed via SPS to conclude the real situation. Fortunately, those who replied; filled and returned their answers within no time, strengthening the view that these sources may speed up learning. In addition, a number of college teachers were present at Quaid-eAzam Academy for Educational Development, Lahore, for Promotion Linked 
Training. A number of them were also approached randomly as control sampling and all replied willingly. Results were compiled and were examined through SPS that is another application on net. Finally, conclusions were made on the basis of literature studied and reflections given by the worthy fellows of various colleges.

\section{FINDINGS AND DATA ANALYSIS}

There are various types of Electronic Media and applications used socially, the study aimed at to get knowledge of few types and uses that are specifically related with the teachers and academics. Namely, the following types were asked about in the questionnaire as Mobiles, Laptops, Internet, and social media like Facebook, WhatsApp, YouTube, Messengers, Twitter, google Classroom, Zoom and also emails. The teachers were asked how they use these, whether to prepare their lectures only or while teaching in the class, too. In addition, if they guide their students too for using these in learning and sharing information with them or in the class room.

Descriptive and frequency analysis was conducted for the analysis of Uses of Electronic Media in College Classes, statement wise of the instrument.

Table 1: Descriptive and frequency analysis of Uses of Electronic Media in College Classes $(N=26)$ about the statement; You use internet for the preparation of lectures? (Q1)

\begin{tabular}{llllll}
\hline \multicolumn{1}{c}{ Scale } & & $\boldsymbol{F}$ & $\boldsymbol{\%}$ & $\boldsymbol{M}$ & $\boldsymbol{S D}$ \\
\hline $\begin{array}{l}\text { (Strongly } \\
\text { disagree) }\end{array}$ & 1 & 3.8 & & \\
2 (disagree) & 5 & 19.2 & & \\
4 (Agree) & 9 & 34.6 & 3.9231 & 1.26248 \\
$5 \quad$ (Strongly & 11 & 42.3 & & \\
Agree) & & & & \\
Total & 26 & 100.0 & & \\
\hline
\end{tabular}

It is indicated in the table 1 that frequency analysis of Uses of Electronic Media in College Classes about the statement; you use internet for the preparation of lectures? (Q1) $(\mathrm{N}=26)$ were strongly disagree $\mathrm{f}=1, \%=3.8$, disagree $\mathrm{f}=5, \%=19$, agree $f=9$, $\%=34.6$, strongly agree $=11, \%=42.3$, on the scale of questionnaire. Descriptive analysis of Uses internet in lecture preparation $(\mathrm{N}=26)$ were $(\mathrm{M}=3.9231, \mathrm{SD}=1.26248)$ on the scale of questionnaire.

It is concluded that descriptive and frequency analysis of uses of the electronic media in college classes about the statement; you use internet for the preparation of lectures? were mostly strongly agreed. Most of the teachers use internet for the preparation of lectures. 


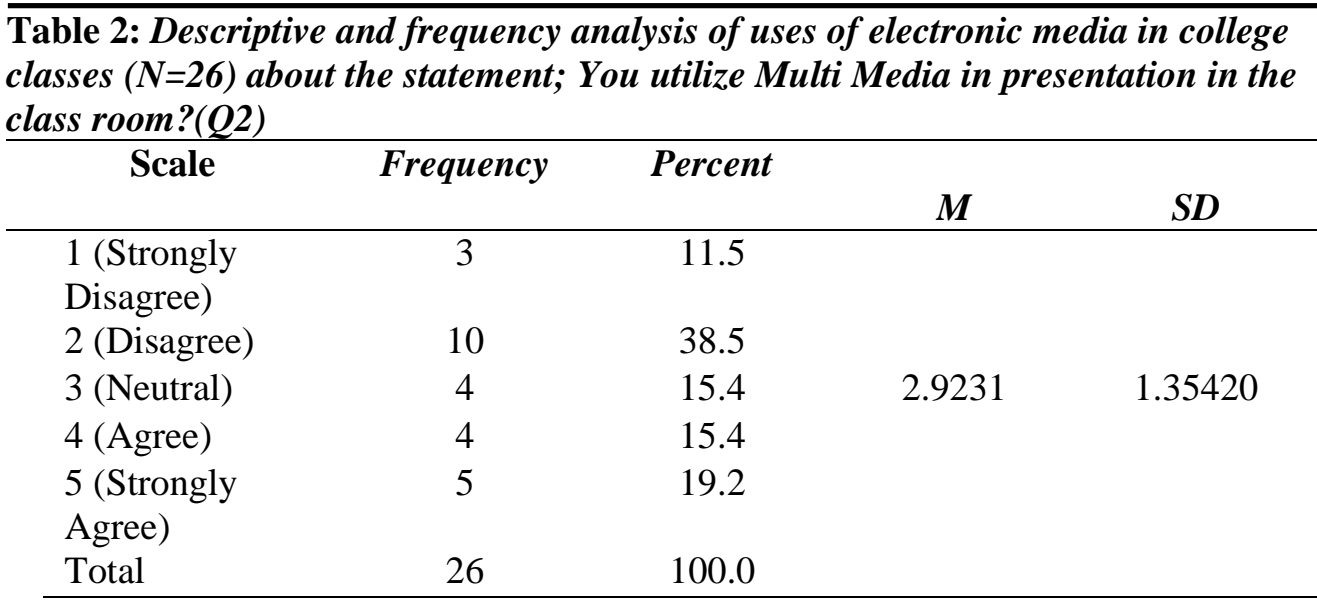

It is indicated in the table 2 that frequency analysis of Uses of Electronic Media in College Classes about the statement; you utilize Multi Media in presentation in the class room? $(\mathrm{Q} 2)(\mathrm{N}=26)$ were strongly disagree $\mathrm{f}=3, \%=11.5$, disagree $\mathrm{f}=10, \%=38.5$, undecided $\mathrm{f}=4, \%=15.4$, agree $\mathrm{f}=4, \%=15.4$, strongly agree $=5, \%=19.2$ on the scale of questionnaire. Descriptive analysis of You utilize Multi Media in presentation in the class room $(\mathrm{N}=26)$ were $(\mathrm{M}=2.9231, \mathrm{SD}=1.35420)$ on the scale of questionnaire.

It is concluded that descriptive and frequency analysis of uses of the electronic media in college classes about the statement; you utilize Multi Media in presentation in the class room? Was mostly neutral that means multimedia is not often used by the teachers. You utilize Multi Media in presentation in the class room is neutral as Multimedia is not used as much by the teachers.

Table 3: Descriptive and frequency analysis of uses of electronic media in college classes $(N=26)$ about the statement; You use laptop for your learning-based activities in the class. (Q3)

\begin{tabular}{lcccc}
\hline \multicolumn{1}{c}{ Scale } & Frequency & Percent & $\boldsymbol{M}$ & SD \\
\hline 1 (Strongly & 3 & 11.5 & & \\
Disagree) & & & & \\
2 (Disagree) & 9 & 34.6 & & \\
3 (Neutral) & 3 & 11.5 & 3.0385 & 1.37057 \\
4 (Agree) & 6 & 23.1 & & \\
5 (Strongly & 5 & 19.2 & & \\
Agree) & & & & \\
Total & 26 & 100.0 & & \\
\hline
\end{tabular}


It is indicated in the table 3 that frequency analysis of Uses of Electronic Media in College Classes about the statement; You use laptop for your learning-based activities in the class? $(\mathrm{Q} 3)(\mathrm{N}=26)$ were strongly disagree $\mathrm{f}=1, \%=11.5$, disagree $\mathrm{f}=9, \%=34.6$, undecided $\mathrm{f}=3, \%=11.5$, agree $\mathrm{f}=6, \%=23.1$, strongly agree $=5, \%=19.2$ on the scale of questionnaire. Descriptive analysis of You use laptop for your learning-based activities in the class $(\mathrm{N}=26)$ were $(\mathrm{M}=3.0385, \mathrm{SD}=1.37057)$ on the scale of questionnaire.

It is concluded that descriptive and frequency analysis of uses of the electronic media in college classes about the statement; You use laptop for your learning based activities in the class? was mostly neutral that means multimedia is not often used by the teachers. You utilize Multi Media in presentation in the class room is neutral as laptop too, is not used as much by the teachers.

Table 4: Descriptive and frequency analysis of uses of electronic media in college classes $(N=26)$ about the statement; You use your android mobiles to clarify your point of view in the class room. (Q4)

\begin{tabular}{lcccc}
\hline \multicolumn{1}{c}{ Scale } & Frequency & Percent & $\boldsymbol{M}$ & SD \\
\hline 1 (Strongly & 2 & 7.7 & 3.6154 & 1.37057 \\
Disagree) & & & & \\
2 (Disagree) & 5 & 19.2 & & \\
4 (Agree) & 13 & 50.0 & & \\
5 (Strongly & 6 & 23.1 & & \\
Agree) & & & & \\
Total & 26 & 100.0 & & \\
\hline
\end{tabular}

It is indicated in the table 4 that frequency analysis of Uses of Electronic Media in College Classes about the statement; You use your android mobiles to clarify your point of view in the class room. $(\mathrm{Q} 4)(\mathrm{N}=26)$ were strongly disagree $\mathrm{f}=2, \%=7.7$, disagree $\mathrm{f}=5 \%=19.2$, agree $\mathrm{f}=13, \%=50$, strongly agree $\mathrm{f}=6, \%=23.1$, on the scale of questionnaire. Descriptive analysis of You use your android mobiles to clarify your point of view in the class room. $(\mathrm{N}=26)$ were $(\mathrm{M}=3.6154, \mathrm{SD}=1.37057)$ on the scale of questionnaire.

It is concluded that descriptive and frequency analysis of uses of the electronic media in college classes about the statement; You use your android mobiles to clarify your point of view in the class room was mostly agreed. The table 4 M 3.6154 concludes use of mobiles by the teachers is agreed.

Table 5: Descriptive and frequency analysis of uses of electronic media in college classes $(N=26)$ about the statement; Internet is improving teaching skills. (Q5)

Scale

Frequency
Percent 


\begin{tabular}{lcccc}
3 (Neutral) & 2 & 7.7 & 4.4231 & \\
4 (Agree) & 11 & 42.3 & & 0.643331 \\
5 ( Strongly & 13 & 50.0 & & \\
Agree) & & & & \\
Total & 26 & 100.0 & & \\
\hline
\end{tabular}

It is indicated in the table 5 that frequency analysis of Uses of Electronic Media in College Classes about the statement; Internet is improving teaching skills. (Q5) ( $N=26)$ were undecided $\mathrm{f}=2 \%=7.7$, agree $\mathrm{f}=11, \%=42.3$, strongly agree $\mathrm{f}=13, \%=50.0$, on the scale of questionnaire. Descriptive analysis of Internet is improving teaching skills $(\mathrm{N}=26)$ were $(\mathrm{M}=4.4231, \mathrm{SD}=0.643331)$ on the scale of questionnaire.

It is concluded that descriptive and frequency analysis of uses of the electronic media in college classes about the statement; Internet is improving teaching skills was agreed that means internet is being used frequently by the teachers.

Table 6: Descriptive and frequency analysis of uses of electronic media in college classes $(N=26)$ about the statement; You communicate your findings notes on WhatsApp? (Q6)

\begin{tabular}{lcccc}
\multicolumn{1}{c}{ Scale } & Frequency & Percent & M & SD \\
\hline 1 (Strongly & 1 & 3.8 & & \\
Disagree) & & & & \\
2 (Agree) & 4 & 15.4 & 3.5769 & 1.02657 \\
3 (Neutral) & 3 & 11.5 & & \\
4 (Agree) & 15 & 57.7 & & \\
5 (Strongly & 3 & 11.5 & & \\
Agree) & & & & \\
Total & 26 & 100.0 & & \\
\hline
\end{tabular}

It is indicated in the table 6 that frequency analysis of Uses of Electronic Media in College Classes about the statement; You communicate your findings notes on Whatsapps? (Q6) $(\mathrm{N}=26)$ were strongly disagree $\mathrm{f}=1, \%=3.8$, disagree $\mathrm{f}=4 \%=15.4$, undecided $\mathrm{f}=3, \%=11.5$, agree $\mathrm{f}=15, \%=57.7$, strongly agree $\mathrm{f}=3, \%=11.5$ on the scale of questionnaire. Descriptive analysis of You communicate your findings notes on WhatsApp. $(\mathrm{N}=26)$ were $(\mathrm{M}=3.5679, \mathrm{SD}=1.02657)$ on the scale of questionnaire.

It is concluded that descriptive and frequency analysis of uses of the electronic media in college classes about the statement; You communicate your findings notes on 
WhatsApp was agreed that means sharing of information and knowledge is widely practiced by the teachers.

Table 7: Descriptive and frequency analysis of uses of electronic media in college classes $(N=26)$ about the statement; You use Youtube to download movies related to your lecture. $(Q 7)$

\begin{tabular}{lcccc}
\hline Scale & Frequency & Percent & M & SD \\
\hline 1 (Strongly & 2 & 7.7 & 3.4231 & 1.13747 \\
Disagree) & & & & \\
2 (Disagree) & 4 & 15.4 & & \\
3 ( Neutral) & 4 & 15.4 & & \\
4 (Agree) & 13 & 50.0 & & \\
5 (Disagree) & 3 & 11.5 & & \\
Total & 26 & 100.0 & & \\
\hline
\end{tabular}

It is indicated in the table 7 that frequency analysis of Uses of Electronic Media in College Classes about the statement; You use Youtube to download movies related to your lecture. (Q7) $(\mathrm{N}=26)$ were strongly disagree $\mathrm{f}=2, \%=7.7$, disagree $\mathrm{f}=4 \%=15.4$, undecided $\mathrm{f}=4, \%=15,4$, agree $\mathrm{f}=13, \%=50$, strongly agree $\mathrm{f}=3, \%=11.5$, on the scale of questionnaire. Descriptive analysis of You use You Tube to download movies related to your lecture. $(\mathrm{N}=26)$ were $(\mathrm{M}=3.4231, \mathrm{SD}=1.13747)$ on the scale of questionnaire.

It is concluded that descriptive and frequency analysis of uses of the electronic media in college classes about the statement; You use You Tube to download movies related to your lecture was neutral, i.e., teachers are careful in using You Tube.

Table 8: Descriptive and frequency analysis of uses of electronic media in college classes $(N=26)$ about the statement; You ask your student to share their material on Facebook. (Q8)

\begin{tabular}{lcccc}
\multicolumn{1}{c}{ Scale } & Frequency & Percent & $M$ & $S D$ \\
\hline $1 \quad$ (Strongly & 3 & 11.5 & & \\
Disagree) & & & & \\
2 (Disagree) & 9 & 34.6 & & \\
3 (Neutral) & 2 & 7.7 & 2.9231 & 1.19743 \\
4 (Agree) & 11 & 42.3 & & \\
5 (Disagree) & 1 & 3.8 & & \\
Total & 26 & 100.0 & & \\
\hline
\end{tabular}


It is indicated in the table 8 that frequency analysis of Uses of Electronic Media in College Classes about the statement; you ask your student to share their material on Facebook. (Q8) $(\mathrm{N}=26)$ were strongly disagree $\mathrm{f}=3, \%=11.5$, disagree $\mathrm{f}=9 \%=34.6$, undecided $\mathrm{f}=2, \%=7.7$, agree $\mathrm{f}=11, \%=42.3$, strongly agree $\mathrm{f}=1, \%=3.8$, on the scale of questionnaire. Descriptive analysis of you ask your student to share their material on Facebook. $(\mathrm{Q} 8)(\mathrm{N}=26)$ were $(\mathrm{M}=2.9231, \mathrm{SD}=1.19743)$ on the scale of questionnaire.

It is concluded that descriptive and frequency analysis of uses of the electronic media in college classes about the statement; you ask your student to share their material on Facebook was disagreed, i.e., teachers are hesitant in suggesting their students to use Facebook.

Table 9: Descriptive and frequency analysis of uses of electronic media in college classes $(N=26)$ about the statement; you give assignments to students which involve use of search Engines? ( $Q 9)$

\begin{tabular}{lcccc}
\hline Scale & Frequency & Percent & $\boldsymbol{M}$ & SD \\
\hline 1 (Strongly & 1 & 3.8 & & \\
Disagree) & & & & \\
2 (Disagree) & 4 & 15.4 & 3.6923 & 1.04954 \\
3 (Neutral) & 1 & 3.8 & & \\
4 (Agree) & 16 & 61.5 & & \\
5 (Disagree) & 4 & 15.4 & & \\
Total & 26 & 100.0 & & \\
\hline
\end{tabular}

It is indicated in the table 9 that frequency analysis of Uses of Electronic Media in College Classes about the statement; You give assignments to students which involve use of search Engines? (Q9) $(\mathrm{N}=26)$ were strongly disagree $\mathrm{f}=1, \%=3.8$, disagree $\mathrm{f}=4$ $\%=15.4$, undecided $\mathrm{f}=1 . \%=3.8$, agree $\mathrm{f}=16, \%=61.5$, strongly agree $\mathrm{f}=4, \%=15.4$, on the scale of questionnaire. Descriptive analysis of You give assignments to students which involve use of search Engines? (Q9) $(\mathrm{N}=26)$ were $(\mathrm{M}=3.6923, \mathrm{SD}=1.04954)$ on the scale of questionnaire.

It is concluded that descriptive and frequency analysis of uses of the electronic media in college classes about the statement; You give assignments to students which involve use of search Engines manifests, that teachers involve their students to use search engines.

TABLE 10: Descriptive and frequency analysis of uses of electronic media in college classes $(N=26)$ about the statement; about the statement; You ask students to share their assignments through electronic mail? (Q10) 


\begin{tabular}{lcccc}
\hline Scale & Frequency & Percent & M & SD \\
\hline 1 (Strongly & 4 & 15.4 & & \\
Disagree) & & & & \\
2 (Disagree) & 7 & 26.9 & 2.9600 & 1.30639 \\
3 (Neutral) & 2 & 7.7 & & \\
4 (Agree) & 11 & 42.3 & & \\
5 (Strongly & 2 & 7.7 & & \\
Agree) & & & & \\
Total & 26 & & & \\
& & 100.0 & & \\
\hline
\end{tabular}

It is indicated in the table 10 that frequency analysis of Uses of Electronic Media in College Classes about the statement; You ask students to share their assignments through electronic mail? (Q10) $(\mathrm{N}=26)$ were strongly disagree $\mathrm{f}=4, \%=15.4$, disagree $\mathrm{f}=7, \%=26.9$, undecided $\mathrm{f}=2, \%=7.7$, agree $\mathrm{f}=11, \%=42.3$, strongly agree $\mathrm{f}=2, \%=7.7$ on the scale of questionnaire. Descriptive analysis of You ask students to share their assignments through electronic mail? $(\mathrm{Q} 10)(\mathrm{N}=26)$ were $(\mathrm{M}=2.9600, \mathrm{SD}=1.30639)$ on the scale of questionnaire.

It is concluded that descriptive and frequency analysis of uses of the electronic media in college classes about the statement; You ask students to share their assignments through electronic mail expressed the teacher's neutral behavior towards students in seeing into search engines.

\section{FINDINGS}

Teacher community uses the electronic media as a tool in preparation and deliverance of their lectures widely.

They do communicate among themselves and share knowledge and thinking.

Use of electronic media is limited for the students in the class, particularly the social media.

Internet is widely used for searching and getting information.

Electronic mails are extensively used as a sharing tool of information and is more appreciated.

Use of social media is discouraged among the students.

There is a dire need of training and understanding of the use of this modern technique by the teachers as well as the students.

\section{DISCUSSION}

Results of the study illustrates that the tools of electronic media are still hesitantly used by the teachers however this trend has been increasing gradually. They use this tool personally for their own preparation of lectures and also take help to deliver lectures 
in the class room. Yet the use in class room is restricted owing to the supposition of misusing and attention diverting devices. The teachers who are more conventional and have belief in teaching in traditional style oppose use of electronic media in class emphatically.

This thinking is not confined to the age group but prevails in all age group with the exception that newly appointed teachers are more attuned to the modern technology and wants to use these in the class as helping techniques. Unavailability of the tools at the institutions also bars this activity. Sometimes the institutions have these techniques at their disposal but the authoritative possession of the head impedes its use and a long persuasion process had to be followed for a positive output.

Socio-cultural restraints and ambiguous concepts about the use of internet have raised the suspicions among the parents. Gender discrimination also cause the limitation of its use. Parents in smaller cities do not aspire for higher education for their daughters and confined to the available education at home city, hence the female students have least access to the electronic media devices.

The present study addresses the possibilities of using the electronic media and its importance with respect to education at college level, and stake holders such as the teachers, students, parents, heads of the institutions and policy makers. It may help the teachers to perceive the necessity of using different kinds of electronic media. It may also create a yearning to learn extensively to the part of the students. The Electronic media is a striking reality of the modern era and teacher community should be aware of its benefits, which they can obtain by using mobiles, multimedia, movies, laptops, internet and various applications of the day.

The study may also motivate the parents to get to be used to these techniques facilitating the children's academic development. As in socio-cultural set up of the country, the supervised use under the guidance of parents and teachers is considered essential.

To understand children's relationships with media and how to build on these constructively is very important. (Cary, 2010) It can be used in developing children's critical skills through watching and analyzing moving image media, so efforts should be made for broadening children's experiences of different kinds of media and their media literacy. It can create activities that promote imaginative thinking and decisionmaking. If the habit of sing electronic media is established, it becomes easier and quicker for the students to understand and expand their learning activities and the teacher may receive the feedback in the same way. Hard copies are time-consuming and expensive, so access of knowledge may be wider. However, it is also a fact that 
hard copies of assignments etc. are needed even then for internal moderator and external examiner

In the colleges of Punjab and the country at large, the emphasis is not on quality education and learning objectives of the students as is illustrated by Bloom (Forehand, 2005) but the head of the institutions, the principal is directed to perform otherwise. $\mathrm{He} / \mathrm{she}$ stresses on discipline and other administrations but nothing is undertaken to produce conducive environment for the learning goals. Hence, the individual use by teachers in the classrooms are proving beneficial and an initiative that may change the environment. Principals should also pay attention and raise their voices for better facilities to be provided to all students and the solo efforts may turn into a collective benefit.

The Stake Holder in this case may be Higher Education Department (HED from now on), may also deliver by the endowment of financial provisions. It also inculcates the institutional interests in promoting literacy by use of media. As literacy by this means may produce the ideals of self-actualization, cultural expression and aesthetic creativity too. It may also achieve a competitive advantage vital to a globalized information scenario. Or, it may be conceived as the key means by which citizens is made to participate more in society and yield more to its progress.

\section{Use of Electronic Media during COVID Pandemic}

This study was originally undertaken in 2018 , but recently owing to the situation of pandemic the importance of the modern media techniques has been enhanced manifold. Even the teachers who had been illiterate of the modern technology have to learn and adopt this any way. The students have to use it too as to watch lectures or to participate the class activities on line. However, difficulties are there for the students as well as the teachers in executing this practice, namely:

The students are dependent of their parents who hesitate to allow the use of internet to their children particularly the female students.

These female students have to use their father's or brother's apparatus under their strict supervision. On the other hand, female teachers have complained for wrong calls and messages which are sometimes harassing but they have to ignore this.

This restriction has resulted in limited know-how of handling and applications and the apparatus, too, barring timely and regular inclusion of the students in class.

The far-off places have limited or no service of internet. The packages introduced by the private companies are limited and proved expensive due to the heavy data transfer 
in delivering lectures. The teachers had to spent more time to learn the techniques owing to having less knowledge of basic techniques, which caused much wastage of time.

Students were able to take fake tests on line, it was observed that whenever classes started manually at campuses after opening lock down, the result was quite different in comparison of those took place on internet. The government emphasized to use of internet and applications for teaching but it did not provide the facilities to improve the process of teaching and learning in smaller cities and far-off areas particularly. Government have not able to check the private mobile and internet companies to curb the hidden charges. The Government itself levied unfair taxes which also lessened the capacity of the consumer to use the packages continuously.

Previous government have endowed lap tops to the eligible students to promote IT culture, it was banned by the present government. Even during the Corona Pandemic, the importance and need of this apparatus could not convince the authorities to provide such apparatus to the needy students. High prices of android mobiles or lap tops have hurled thousands of children back in the struggle to get education. This phenomenon is alarming as the literacy rate in the country is already lagging far behind even most of the developing countries in the world and all the neighboring countries of the region.

Online trainings for the teachers were arranged at times, however, the orientation and effectiveness of these trainings remained limited. Those who got training had to face almost all the burden of the institutions' online managements. Higher authorities have high expectations from the workers in field including teachers but their policies have not seemed to involve the main stake holders; the teachers, students and the parents, in policy-making process. The teachers are assigned tasks other than teachings like rationing flour, sugar, election duties as well as counting and data collecting during census which decreases their deficiency in teaching. The communication through modern techniques is still difficult which hinder the learning and understanding process.

\section{RECOMMENDATIONS}

Electronic tools make classes more efficient, lectures more compelling, informative and varied; reading assignments more extensive, interesting and accessible; discussion more free ranging, and challenging; and student's paper more original and well researched. These may advance the higher goals of teachers. (Brinkley, 1999) Technology also offers advantages in terms of access for other non-traditional students as well as international ones, namely careers, the employed, full or part time, or others for whom flexible provision and non-conventional approaches to timetabling are essential. E-support is not time restricted since every aspect of the teaching and 
learning process can be recorded and archived for access at any time, 24/7 from anywhere. (Sweeney, 2009).

Therefore, higher authorities may facilitate the teachers as well as the teaching process in the county, particularly in the smaller cities where most of the amenities are neglected, to enhance the usefulness of electronic media that may in turn produce conducive environment for effective communication and learning. As it, the electronic media, complements the elements of teaching in less time, increasing efficiency in the classroom. Researchers should also be aided financially to accomplish researches in context of the particular conditions of the country or region like those innumerable research agencies in modern world, who help in decision making by undertaking extensive research works in context of their own countries, regions and even the developing world.

It may be concluded on the basis of the study that there is a zeal to use these tools by the teachers, however the results of the survey show that it is still far away to access more sophisticated objective and systematic learning. It opens more vistas of research by raising wide variety of questions and needed to be find out by the researchers, e.g., What is electronic media literacy? How is it changing the society? And what are its uses? How policy makers may enhance the initiatives for its positive and productive use? Who may be benefitted by improving the electronic media tools; all the stake holders of the system; teachers, students, parents, policy makers and finally the society as a whole? How the use of electronic media tools and applications be used safely in conventional and suppressed society like Pakistan.

\section{REFERENCES}

Sriram, Arulchelvan \& D. Viswanathan. (2006). Role and effectiveness of electronic media in higher education-with special reference to Tamilnadu. The Turkish Online Journal of Distance Education. 7, (4)

Bazalgette, Cary. ed. (2010) Teaching Media in Primary Schools, retrieved from https://in.sagepub.com/en-in/sas/teaching-media-in-primary-schools/book234628, Sage Publishing.

Brinkley, Alan. Betty Dessants \& Micheal Flamm. (1999) "Using Electronic Resources for Teaching," The Chicago Hand Book for Teachers: A Practicle guide to the College Classroom. Retrieved from www.press.uchicago.edu/Misc/Chicago/075125.html on July 11, 2018.

Chimenti, Paula. Roberto Nogueira, Jose Afonso Mazzon, Marco Rodrigues, Luiz Felipe Hupsel (2014). "Electronic Media Use: Towards an Integrative Model." Journal of Global Information Management. 22 (1). 51-69. 
Forehand, M. (2005). Bloom's taxonomy: Original and revised. In M. Orey (Ed.), Emerging Perspectives on learning, teaching, and technology. Retrieved on July 11, 2018 from http://projects.coe.uga.edu/epltt/

Livingstone, Sonia. (2003) The Changing Nature and Uses of Media Literacy, Paper 4 in Dr. Rosalind Gill, Dr. Andy Pratt, Dr. Terhi Rantanen and Dr. Nick Couldry. (Eds). MEDIA@LSE Electronic Working Papers.

Mondal, Puja. "Positive Effects of Electronic Media on Society and Culture." Your Article Library. Retrieved from www.ypurarticlelibrary.com on June 30, 2018.

Sweeney, Simon. (2009) "Internationalisation and the use of electronic media in teaching and assessment. Live webinars and audio feedback: apparent benefits and drawbacks." Routledge, Retrieved from https://doi.org/10.11120/elss.2009.02010009 on July 08, 2018.

Setzer, Valdemar W. (2001) "Electronic Media and Education:

Television, Video Game and Computer." Department of Computer Science, University of São Paulo, Brazil. Retrieved on June 30, 2018 from www.ime.usp.br/ vwsetzer. 